\title{
Hepatoprotective Effects of
} Nasturtium Officinale and Allium Polyanthum Extracts on CCL4Induced Hepatic Damage In Albino

\section{Rats}

\author{
Zana Hassan Ibrahim \\ Department of Medical Laboratory Science \\ College of Science \\ University of Raparin \\ Ranya, Iraq \\ zana@uor.edu.krd
}

Rebaz Rebwar Mala

Department of Medical Laboratory Science

College of Science

University of Raparin

Ranya, Iraq

rebaz.rebwar@uor.edu.krd

\author{
Shkar Rzgar K. Rostam \\ Department of Biology \\ College of Science \\ University of Sulaimany \\ Sulaimany, Iraq \\ shkar.rostam@univsul.edu.iq
}

Soran Qadir Abdul

Department of Medical Laboratory Science

College of Science

University of Raparin

Ranya, Iraq

soran.qadr@uor.edu.krd

\begin{tabular}{l} 
Article Info \\
\hline Volume 6-Issue 2- \\
December 2021 \\
DOI: \\
10.24017/science.2021.2.12 \\
Article history: \\
Received 10/10/2021 \\
Accepted 24/1/2022 \\
\hline
\end{tabular}

Keywords:

Carbon tetrachloride, $\mathrm{CCL}_{4}$ Hepatotoxicity, Hepatic damage, Rat, Nasturtium officinale and Allium polyanthum.

\begin{abstract}
The present study was designed to explore and distinguish the potential hepatoprotective properties of Nasturtium officinale and Allium polyanthum plant extracts in liver injury model using CCLA at animal model. We use five groups of six rat replicants were separated from thirty (30) healthy male Albino rats randomly: Normal control (NC), Positive control (Pos-C), Nasturtium officinale extract (NOE), Allium polyanthum extract (APE), and NOE + APE. The animals had free access of feeding (standard rat diet) and drinking (distilled water). Except for $\mathrm{NC}$ rats, all other groups were exposed to Carbone tetrachloride (CCL4) at every 72 hours for 3 weeks to induce hepatic damage. Corresponding treatments were established to the respective groups during study period. Levels of Aspartate aminotransferase (AST), Alanine aminotransferase (ALT), Alkaline phosphatase (ALP), Total serum bilirubin (TSB), Total protein (TP), Albumin (ALB) and malondialdehyde (MDA) were measured in serum when the study have ended. Histopathological analysis of the liver sections was also determined. Our results illustrate that, CCL4-treated rats were showed significant increases $(p<0.05)$ in serum enzyme activities (AST, ALT, \& ALP), TSB and MDA levels; reflecting hepatocellular damage caused by CCL4 as a comparison with $N C$ group rats, whereas the values of serum TP with $A L B$
\end{abstract}


were decreased. Furthermore, the histological examination of liver tissues showed that $\mathrm{CCL}_{4}$ triggered several histological variations at the tissue level. Treatments of NOE and/or APE along with CCL4 for 3 weeks were significantly improved the CCL4-caused variations in the respective blood-biochemical parameters and histological study of the liver by comparing with Pos-C rats indicating the protection of hepatic cells. In conclusion, treatments with NOE and APE either in separate or in combination have shown significant improvement in CCL4-induced hepatopathy in experimental rats as evidenced by observed results in serum and hepatic histopathological examinations.

Copyright $(2021$ Kurdistan Journal of Applied Research. All rights reserved.

\section{INTRODUCTION}

Liver is a largest solid organ in body. Despite it's vital role in body metabolites, it play pivotal role in maintenance and regulating body homeostasis [1]. In addition with numerous performance of metabolic functions [2]; liver organ is the major site of detoxification and also regarded as the primary target organ to all the consumed and administered chemicals or drugs, therefore, excess exposure to chemical toxins could induce hepatocellular injury and this may affect the life quality and health status [3].

Diseases cause liver failure, are remarkably lethal and liver complications still remains as a serious health problem globally [4] even after a conspicuous progression in the field of hepatology in latest years [5]. Hepatic illnesses are arises from hazardous chemicals, continual consumptions of alcohol, chronical-infections and/or autoimmune diseases [6]. These factors will cause damage to the liver organ. As a result of that; by production of highly reactive agents like reactive oxygen species (ROS), gradual development of fat deposition started within hepatocytes to severe hepatitis, cirrhosis of liver, and finally hepatocellular carcinoma (HCC) [7, 8]. A group of chemical compounds have been experimentally implicated in semblance of liver damage including carbon tetrachloride (CCL4) which is mostly commonly used [9].CCL 4 is a powerful and classic toxic agent that is commonly used in animal models for a rapid generation of patho-physiological liver injury that could representing as of human $[3,10]$.

The fundamental mechanism by which $\mathrm{CCL}_{4}$ can cause hepatotoxicity is the creation of extremely reactive intermediates by the action of the hepatic microsomal enzyme system [6] and this strictly resembling the human liver sickness in both morphological and biochemical features of the hepatic cell lesions [11]. Despite that, CCL4 could also disrupts the antioxidant enzyme-system of the liver [9] which lead to incapacitate to perform of it's natural function for deactivation of ROS in cells [12] .

At this time, a limited hepatoprotective medications are obtainable for the management of liver diseases [5]. Hence, the dealing with hepatopathy is remained as a challenge to the current health science yet. Several earlier studies were reported that plant-derived natural substances possess strong antioxidants such as phenol compounds and flavonoids and can interestingly act in $\mathrm{CCL}_{4}$-caused liver damage because they could share free radical scavenging properties [13] and described to exert anti-inflammatory activity [14]. So, the use of phytochemicals in management of chronic liver diseases is focus point because of the conventional drug's high cost, undesirable drug side effects, and their inefficacy [2].

Belonging to this context, this study was intended to establish a liver damage model and assess the potential hepato-protective actions of Nasturtium officinale (watercress) and Allium polyanthum pre-treatment plant extracts in $\mathrm{CCL}_{4}$-caused hepatopathy at rat model. 


\section{METHODS AND MATERIALS}

\subsection{Collection of Plant Samples:}

Nasturtium officinale and Allium polyanthum whole plants were collected around Ranya district/ Kurdistan region/ north of Iraq; in the month of February and March 2021. The whole plants were dried at room temperature away from direct sunlight exposure, pulverized and supplied as pulverized dried material for the study.

\subsection{Preparation of Plant Extracts:}

The dry Powders of Nasturtium officinale and Allium polyanthum plants were separately extracted with ethanol 95\% solvent by using a Soxhlet extractor. After exhaustive extraction processes (10 cycles, $100 \mathrm{gm} / 250 \mathrm{ml}$ of solvent), the extracts of each plant were filtered by using filter paper and then concentrated completely by simple distillation process. The yields were $\sim 10.81 \mathrm{gm}$ and $13.9 \mathrm{gm}$ respectively. The extracts were separately stored in airtight-dark containers at refrigerator until use.

\subsection{Laboratory Animals:}

Thirty (30) male gender Wistar albino rats (Rattus norvegicus) of 150-180 gm body weight in a good physical shape were used at the present study. Males were preferred to avoid the physiological changes due to the oestrus cycle of female genders which repeats at every 4-6 days [15]. The experiment was achieved between Apr-2021 and May-2021 at the department of medical laboratory science (Animal house) /Faculty of Science / University of Raparin.

The rats were maintained in plastic cages bedded with dry wooden chips and were kept at a controlled standard environment (Temperature of $22 \pm 4 \mathrm{C}^{\circ}$ with12:12-hour photoperiod) and were had freely access of feeding (usual rodent diet) and drinking (distilled water).

\subsection{Evaluation of Acute Toxicity:}

For investigating the acute toxicity study of the two plant extracts in experimental rats; Twelve (12) hour fasted animals $(n=12)$ were randomly selected and divided into two equal groups $(n=6)$. NOE and APE in the dose of 300 milligram for each kilogram of rat BW were orally administered correspondingly, then administered rats continuously examined for three (3) upcoming hours; and finally, overnight mortality if any was recorded [16].

\section{5. $\mathrm{CCl}_{4}$-induced Hepatotoxicity:}

For induction of liver injury, a combination of $\mathrm{CCL}_{4}$ with sterile olive oil at 1:1 (v/v) was injected to the experimental rats through intraperitoneal route $(1 \mathrm{~mL}$ of mixture for a $\mathrm{kg}$ of rats body weight) until the study was ended (21 days) at every 72 hours [5].

\subsection{Experimental plan:}

Animals were indiscriminately separated for 5 groups $(n=6)$ and were treated as followings.

Group I: Normal control (NC): Received standard rat diet and distilled water for 3 weeks.

Group II: Positive control (Pos-C): Received CCL 4 (1 ml/kg BW., i.p.) at every 72 hours for 3 weeks.

Group III: (NOE) Received NOE (300 mg/kg BW. 6 days/week) by oral gavage for 3 weeks and simultaneously administered with $\mathrm{CCL}_{4}(1 \mathrm{ml} / \mathrm{kg} \mathrm{BW}$ i.p. $)$ at every 72 hours.

Group IV: (APE) Received APE (300 mg/kg BW., 6 days/week) by oral gavage for 3 weeks and simultaneously administered with $\mathrm{CCL}_{4}(1 \mathrm{ml} / \mathrm{kg}$ BW., i.p. $)$ at every 72 hours.

Group V: (NOE + APE) Received mixture of APE + APE (1:1, $300 \mathrm{mg} / \mathrm{kg}$ BW., 6 days/week) by oral gavage for 3 weeks and simultaneously administered with $\mathrm{CCL}_{4}(1 \mathrm{ml} / \mathrm{kg}$ BW., i.p.) at every 72 hours.

The Pos-C group rats were served as model group and received an equivalent volume of distilled water through oral gavage for 3 weeks. Once the study was finished (48 hours following the last injection of the drug-dosage); animals were separated from diet for the night, anesthetized by ethyl-ether then cardiac-puncturing technique was used for blood collection, allowed to coagulate in evacuated gel tubes at room temperature. Serum fractions were obtained by centrifugation (2500 RPM for 15 minutes) and were used in the assessment of liver function status. Liver organs were also excised, cleansed by normal saline and putted in formaldehyde (10\%) for hepato-histological examinations. 


\subsection{Measurement of Serum Liver Function Markers:}

The serum biochemical markers of hepatic function such as Aspartate aminotransferase (AST), Alanine aminotransferase (ALT), Alkaline phosphatase (ALP), Total serum bilirubin (TSB), Total protein (TP) and Albumin (ALB) concentrations were measured by using fully automated chemistry analyzer (Cobas c-111). Serum malondialdehyde (MDA) concentration was calculated by spectrophotometer with a TBA solution as the procedure previously described by study [15].

\subsection{Histological study:}

The histopathological examination conducted as described by [17] procedure. The whole liver organ from rats of different groups were washed by normal saline, then the desired sections of the liver samples were fixed at $10 \%$ formaldehyde and further followed for hepatopathological findings.

\subsection{Statistical Data Analysis:}

A computer program (SPSS software, Version 24.0) was applied for analysis of the corresponding data from present study. Results were showed as mean \pm standard error (mean \pm SE). The statistical differences were determined by Duncan's test through analysis of variance (One-way ANOVA) and the statistical probability is $\mathrm{P}<0.05$.

\section{RESULTS}

The hepatoprotective effects of ethanolic extracts of Nasturtium officinale and Allium polyanthum plants on serum transaminase enzymes (AST and ALT), ALP, TSB, TP, ALB and MDA levels in $\mathrm{CCL}_{4}$-intoxicated rats were summarized at Table 1.

Compared to the control group; the rats from POS-C group were subjected to $\mathrm{CCL}_{4}$ treatment alone were showed a severe abnormal functioning of hepatic cells, this demonstrated by significant elevations $(\mathrm{p}<0.05)$ in serum markers of AST, ALT and ALP enzymes as well as TSB and MDA while the levels of serum TP and ALB were markedly decreased. The difference in serum ALB level was not significant.

Administration of $\mathrm{CCL}_{4}$ alone were also caused a noticeable histological change in the hepatic tissues of experimental rats including mild to moderate chronic inflammatory cells infiltration (predominantly lymphocytes), vascular congestion, mild to moderate focal fatty change and focal aggregate of atypical cells with hyperchromatic large nuclei as it compared to $\mathrm{NC}$ rats. Oral-gavage pre-treatments of NOE and APE either in separate or in combination mode were significantly $(p<0.05)$ restored the level of raised marker enzymes of serum, levels of TSB and MDA close to the normal level when compared with Pos-C rats. (Table 1 and Figure 1).

Table 1: Effects of plant extracts (NOE and APE) on various biochemical parameters in rats were subjected to hepatotoxicity by carbone tetra chloride injection.

\begin{tabular}{|c|c|c|c|c|c|}
\hline \multirow[t]{3}{*}{ Parameters } & \multirow[t]{3}{*}{ NC } & \multicolumn{4}{|c|}{ CCL4-induced hepatic damage groups } \\
\hline & & \multirow[t]{2}{*}{ Pos-C } & \multicolumn{3}{|c|}{ Plant extracts $(300 \mathrm{mg} / \mathrm{kg} \mathrm{BW})$} \\
\hline & & & NOE & APE & $\mathrm{NOE}+\mathrm{APE}$ \\
\hline AST (IU/L) & $104.33 \pm 5.71^{\mathrm{a}}$ & $683.90 \pm 91.96^{\mathbf{b}}$ & $164.40 \pm 7.90^{\mathrm{a}}$ & $155.11 \pm 9.63^{\mathrm{a}}$ & $148.33 \pm 14.41^{\mathrm{a}}$ \\
\hline ALT (IU/L) & $47.83 \pm 1.62^{\mathrm{a}}$ & $124.41 \pm 49.51^{\mathbf{b}}$ & $34.60 \pm 2.30^{\mathrm{a}}$ & $31.11 \pm 2.99^{\mathrm{a}}$ & $39.35 \pm 3.04^{\mathrm{a}}$ \\
\hline $\operatorname{ALP}(I U / L)$ & $152.83 \pm 9.45^{\mathrm{a}}$ & $219.50 \pm 7.98^{\mathbf{b}}$ & $174.00 \pm 13.51^{\mathrm{a}}$ & $174.50 \pm 14.96^{\mathrm{a}}$ & $182.17 \pm 13.29^{\mathrm{a}}$ \\
\hline TSB (mg/dl) & $0.166 \pm 0.03^{\mathrm{a}}$ & $0.750 \pm 0.13^{b}$ & $0.065 \pm 0.006^{\mathrm{a}}$ & $0.096 \pm 0.033^{\mathrm{a}}$ & $0.103 \pm 0.022^{\mathrm{a}}$ \\
\hline TP (mg/dl) & $5.801 \pm 0.11^{\mathbf{b}}$ & $4.463 \pm 0.47^{\mathrm{a}}$ & $6.330 \pm 0.21^{b}$ & $5.990 \pm 0.32^{\mathbf{b}}$ & $5.905 \pm 0.45^{b}$ \\
\hline ALB (mg/dl) & $3.390 \pm 0.04^{\text {ab }}$ & $2.956 \pm 0.31^{\mathrm{a}}$ & $4.06 \pm 0.20^{b}$ & $3.84 \pm 0.24^{\mathbf{b}}$ & $3.93 \pm 0.27^{b}$ \\
\hline MDA $(\mu \mathrm{mol} / \mathrm{l})$ & $1.671 \pm 0.06^{\mathrm{a}}$ & $3.513 \pm 0.08^{\mathrm{c}}$ & $2.483 \pm 0.24^{\mathbf{b}}$ & $2.060 \pm 0.25^{\mathrm{ab}}$ & $2.353 \pm 0.23^{\mathbf{b}}$ \\
\hline
\end{tabular}

The same letters indicate that differences were insignificant, while the different letters be a sign of significant differences. 


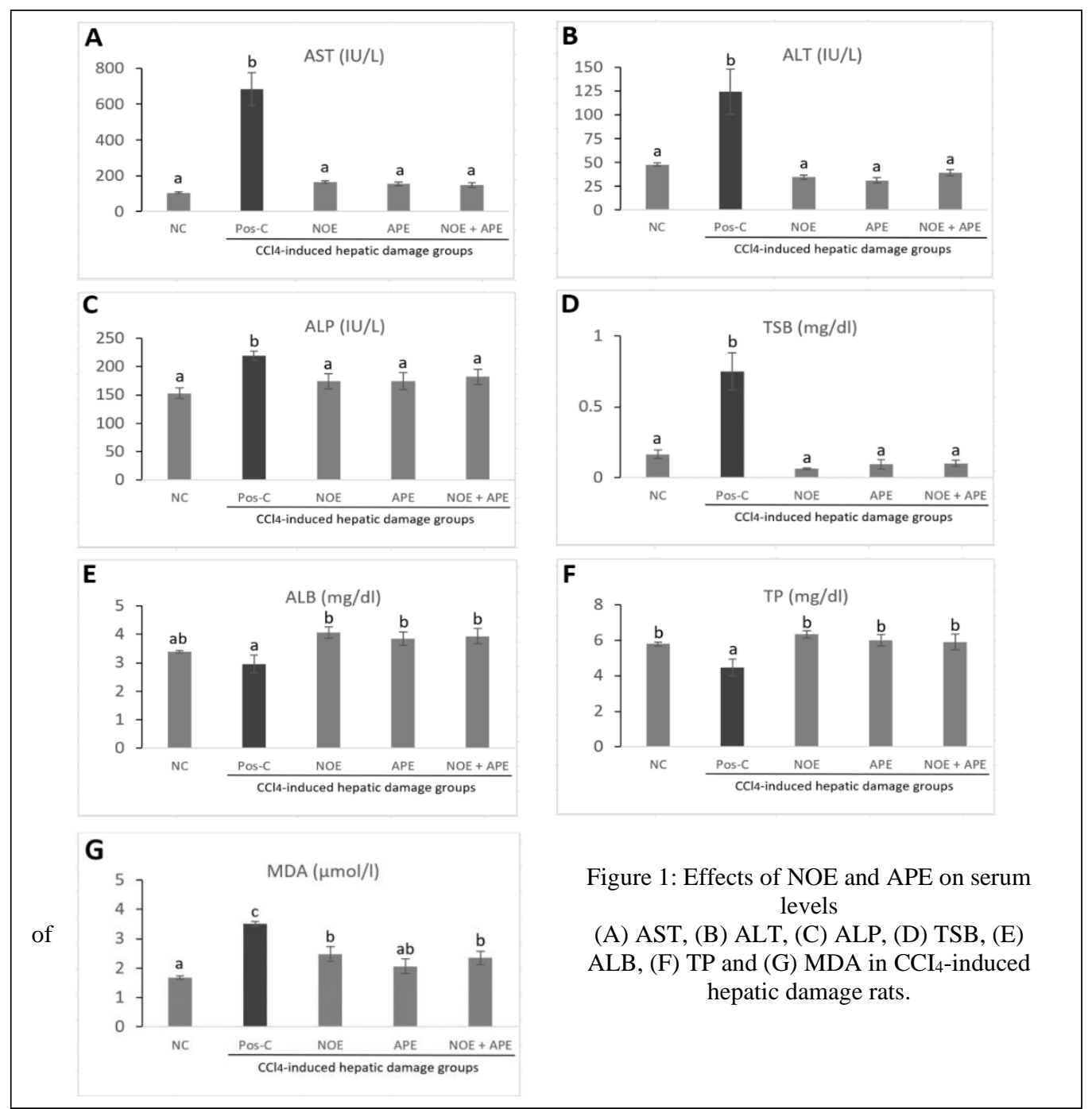

Figure 1: Effects of NOE and APE on serum levels of (A) AST, (B) ALT, (C) ALP, (D) TSB, (E) ALB, (F) TP and (G) MDA in CCI4-induced hepatic damage rats.

In histopathological study; the treatments of NOE and APE revealed significant hepatocellular protection against $\mathrm{CCL}_{4}$-intoxication, which is noticeable by the existence of further or fewer normal hepatocytes and reduced inflammatory infiltration and necrosis comparing with $\mathrm{CCL}_{4-}$ injected group (Figure 2). 


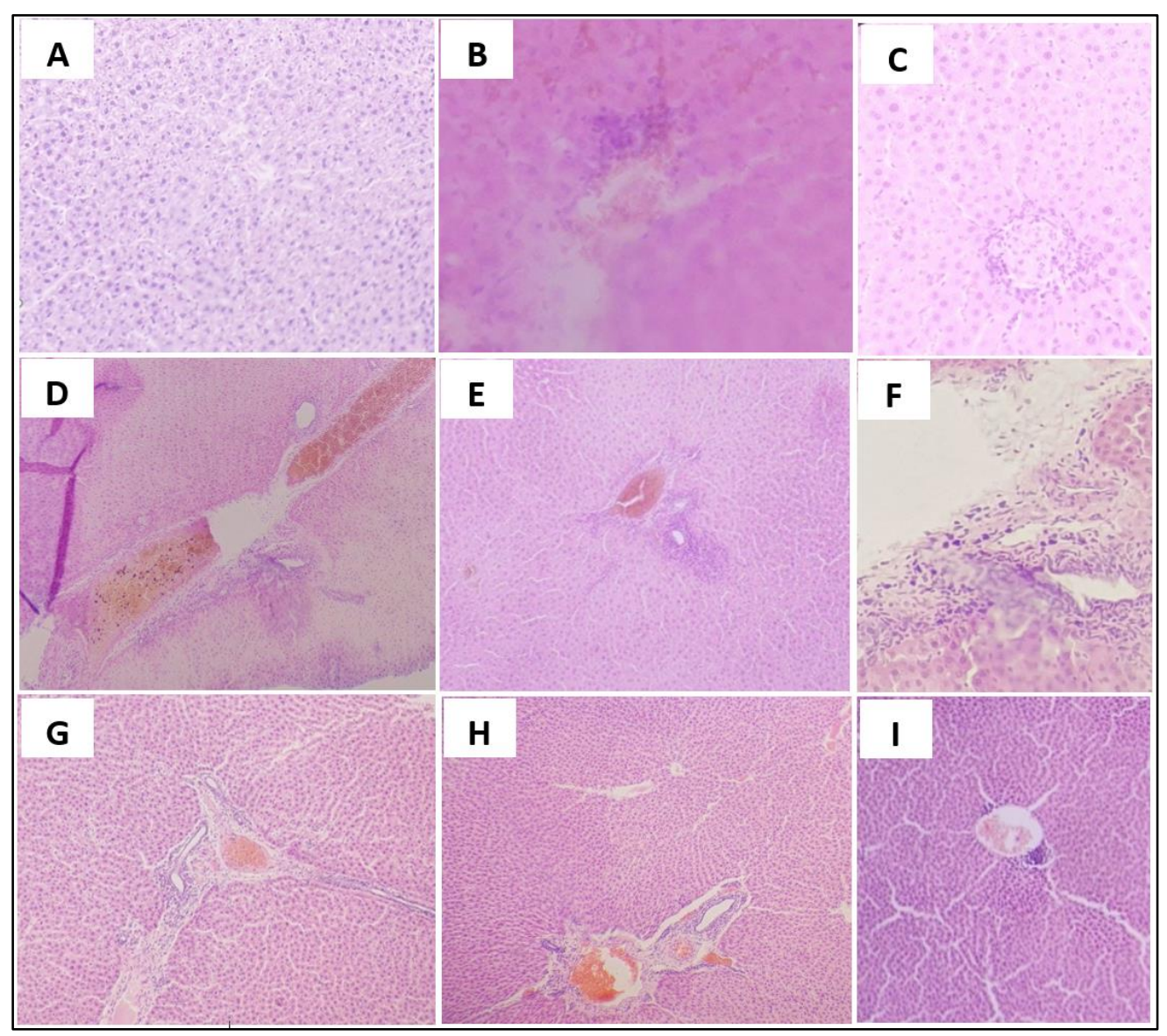

Figure 2: Effects of NOE and APE in rat liver histology against Carbone tetrachloride hepatic injurymodel at male albino rats.

(A) NC: Normal histological arrangement of hepatocytes and central hepatic venule with portal tracts ; (B, C, D, E \& F) Pos-C rats (Model group): Showing mild to moderate chronic inflammatory cells infiltration (predominantly lymphocytes), vascular congestion, mild focal fatty change and focal aggregate of atypical cells with hyperchromatic large nuclei; (G) NOE: Mild chronic inflammatory cells infiltration; (H) APE: Mild chronic inflammatory cells infiltration with no atypical cells; (I) NOE+APE: Mild chronic inflammatory cells infiltration with no atypical cells.

\section{DISCUSSION}

Carbon tetrachloride $\left(\mathrm{CCL}_{4}\right)$ is broadly used in investigational study of acute liver disease model at experimental laboratory animals [13] and its involvement in building of liver dysfunction has been examined for lots of years [18], $\mathrm{CCL}_{4}$ thought to trigger the oxidative stress as a consequence of free radical production and lipid peroxidation at liver [10] in which the normal balance between pro-oxidant and antioxidant system of the cells have been interrupted [19].

Data from the current study were clearly showed that intraperitoneal administration of $\mathrm{CCL}_{4}$ in Pos- $\mathrm{C}$ rats were caused a significant hepatic injury as it confirmed by a sharp increase in liverfunction marker enzymes and ALP, moreover; the TSB with serum MDA concentrations were also significantly increased with a slight depletion of TP and ALB levels (Table 1). These findings were noticeably going parallel with the data from previous studies including $[4,20,22]$. 
Based on the histopathological investigations in the rats were received current hepato-toxicant were also showed mild to moderate chronic inflammatory cells infiltration (predominantly lymphocytes), vascular congestion, mild focal fatty change with focal aggregate of atypical cells with hyperchromatic large nuclei. The same results were observed by [1] study after four weeks of CCL4 administration.

Serum transaminase enzymes are typically representing as the markers of hepatic cellular injury and abnormal functioning [23], because these enzymes are situated in liver cells and were drip out into the circulation during hepatic cell membrane damage [15]. Study by [24] also argued that when hepatic cells were metabolize $\mathrm{CCL}_{4}$, cellular transe-nzyme contents were directly leaked into the blood stream by hepatic tissues, and this caused a substantial increases in the amount of these serum maker enzymes at blood.

The principal mechanisms by which CCL4 can trigger hepatic functional abnormality is the invention of reactive-free radicals when metabolized [25] these free radicals are chemically unstable; directly could initiate damage to several important cellular-bio-macromolecules such as proteins, lipids, and nucleic acids [13], they able to enhance lipid peroxidation on the hepatocyte plasma membrane, altering the enzyme actions and finally encouraging liver tissue damage [1] and study by [14] confirmed that oxidative stress and lipid peroxidation are strongly interrelated. The obtained results in serum transaminase enzymes and MDA by this study were consistent with earlier studies and strongly support that $\mathrm{CCL}_{4}$ intoxication caused oxidative stress in Pos- $\mathrm{C}$ model rats. Accordingly, elimination or inhibition of the reactive radical generations and rebalancing of the disturbed antioxidant status have been targeted in the health managements of hepatic damage $[18,26]$.

Based on the acquired results by present study; it could be revealed that treatments of NOE and APE either in separate or as co-treatments were suggestively restored or prevented the CCL4-induced hepatic cell injuries toward normalization nearly as manifested by marked decreases in the concentration of liver-marker enzyme activities, restoration in the levels of serum TSB, TP, ALB as well as MDA in the respective groups as compared to untreated CCL4 group. The histological features of treatment groups were not fully enhanced by this study but expanse of histopathological injuries were showed that the focal aggregation of atypical cells with hyperchromatic large nuclei reduced at pretreatment groups and this could provide supportive evidence for biochemical analysis. These findings suggest that both NOE and APE may effectively protect hepatocytes from carbon tetrachloride intoxication and this could define their health promoting features.

The use of medicinal plants were previously suggested by a lot of studies [27]. Some phytochemicals have been proven to prevent inflammation through decrease in the production of pro-inflammatory factors by macrophages or blocking inflammatory pathways downstream and or help for the syntheses of antioxidant enzyme systems of the body and detoxification pathway at the transcriptional level [14].

Previous studies [23, 28] were demonstrated that hepatoprotective activity of compounds verified either by decreasing the harmful effects of hepatotoxic compound or by maintaining the normal hepatic physiology and reversing the histological damage induced by CCL4. Plants are rich in secondary metabolites; such as phenolic compounds, which can act as antioxidants, based on the presence of redox properties [13]. different studies have clarified that plant extracts have antioxidant properties and were dependable for fight against CCL4 hepatotoxicity [8].

The principal mechanisms by which NOE and APE displayed their protective action on CCL4induced alternations at liver tissues could be attributed to the presence of potential antioxidants at the composition of these two respective plant extracts [2] or by repairing the liver cell membrane and mitochondrial damage and or may be due to their capabilities in blockage of toxicant bioactivation during metabolism and reducing oxidative stress through chelating of available free radicals [6] which was inveterate by the observed results from the current study. 


\section{CONCLUSION}

The present findings could imply supportive evidence that pretreatments of NOE and APE either in separate or in combinations could protect or reinstate the liver from damage at rat $\mathrm{CCL}_{4}$-treated model compared with the $\mathrm{CCL}_{4}$ alone treated group; possibly through the reduction in oxidative stress and inflammation. This may applicable in the control or managements of liver diseases in health care sectors. However, further studies will be necessary for diagnosis of the corresponding active compounds and molecular mechanisms behind the liver-protective effects of these two plants.

\section{REFERENCE}

[1] H. E. EL Sayed, L. E. Morsy, T. M. Abo Emara, and R. A. Galhom, "Effect of carbon tetrachloride $(\mathrm{CCl} 4)$ on liver in adult albino rats: histological study," The Egyptian Journal of Hospital Medicine, vol. 76, no. 6, pp. 4254-4261, 2019.

[2] N. Aghel, I. Rashidi, and A. Mombeini, "Hepatoprotective activity of Capparis spinosa root bark against CCl4 induced hepatic damage in mice," 2007.

[3] B. El-Aarag, A. Khairy, S. A. Khalifa, and H. R. El-Seedi, "Protective Effects of Flavone from Tamarix aphylla against CCl4-Induced Liver Injury in Mice Mediated by Suppression of Oxidative Stress, Apoptosis and Angiogenesis," International journal of molecular sciences, vol. 20, no. 20, pp. 5215, 2019.

[4] R. K. Giri, A. Bose, and S. K. Mishra, "Hepatoprotective activity of Tagetes erecta against carbon tetrachloride-induced hepatic damage in rats," Acta Poloniae Pharmaceutica n Drug Research, vol. 68, no. 6, pp. 999-1003, 2011.

[5] M. G. Palanivel, B. Rajkapoor, R. S. Kumar, J. W. Einstein, E. P. KUMAR, M. R. KUMAR, K. KAVITHA, M. P. KUMAR, and B. JAYAKAR, "Hepatoprotective and antioxidant effect of Pisonia aculeata L. against CCl4-induced hepatic damage in rats," Scientia pharmaceutica, vol. 76, no. 2, pp. 203-216, 2008.

[6] K. Hegde, and A. B. Joshi, "Hepatoprotective and antioxidant effect of Carissa spinarum root extract against CCI4-and paracetamol-induced hepatic damage in rats," || Bangladesh Journal of Pharmacology, vol. 5, no. 1, pp. 73-76, 2010.

[7] T. Jayakumar, E. Ramesh, and P. Geraldine, "Antioxidant activity of the oyster mushroom, Pleurotus ostreatus, on CCl4-induced liver injury in rats," Food and chemical toxicology, vol. 44, no. 12, pp. 1989-1996, 2006.

[8] A. Srivastava, and T. Shivanandappa, "Hepatoprotective effect of the root extract of Decalepis hamiltonii against carbon tetrachloride-induced oxidative stress in rats," Food chemistry, vol. 118, no. 2, pp. 411-417, 2010.

[9] O. A. Adesanoye, and E. O. Farombi, "Hepatoprotective effects of Vernonia amygdalina (astereaceae) in rats treated with carbon tetrachloride," Experimental and Toxicologic Pathology, vol. 62, no. 2, pp. 197-206, 2010.

[10] A. T. Williams, and R. F. Burk, "Carbon tetrachloride hepatotoxicity: an example of free radical-mediated injury." pp. 279-284.

[11] M. Ahn, J. S. Park, S. Chae, S. Kim, C. Moon, J. W. Hyun, and T. Shin, "Hepatoprotective effects of Lycium chinense Miller fruit and its constituent betaine in CCl4-induced hepatic damage in rats," Acta histochemica, vol. 116, no. 6, pp. 1104-1112, 2014.

[12] C.-F. Tsai, Y.-W. Hsu, W.-K. Chen, W.-H. Chang, C.-C. Yen, Y.-C. Ho, and F.-J. $\mathrm{Lu}$, "Hepatoprotective effect of electrolyzed reduced water against carbon tetrachloride-induced liver damage in mice," Food and Chemical Toxicology, vol. 47, no. 8, pp. 2031-2036, 2009.

[13] A. Laouar, F. Klibet, E. Bourogaa, A. Benamara, A. Boumendjel, A. Chefrour, and M. Messarah, "Potential antioxidant properties and hepatoprotective effects of Juniperus phoenicea berries against CCl4 induced hepatic damage in rats," Asian Pacific journal of tropical medicine, vol. 10, no. 3, pp. 263-269, 2017. 
[14] J.-S. Deng, Y.-C. Chang, C.-L. Wen, J.-C. Liao, W.-C. Hou, S. Amagaya, S.-S. Huang, and G.-J. Huang, "Hepatoprotective effect of the ethanol extract of Vitis thunbergii on carbon tetrachloride-induced acute hepatotoxicity in rats through antioxidative activities," Journal of Ethnopharmacology, vol. 142, no. 3, pp. 795-803, 2012.

[15] R. H. Hussein, and Z. H. Ibrahim, "Influence of Omega-3 and Green Tea Extract on Alcohol-Induced Liver Injury in Rats," Kurdistan Journal of Applied Research, pp. 107-116, 2018.

[16] Z. A. Malik, and P. L. Sharma, "An ethanolic extract from licorice (glycyrrhiza glabra) exhibits anti-obesity effects by decreasing dietary fat absorption in a high fat diet-induced obesity rat model," International Journal of Pharmaceutical Sciences and Research, vol. 2, no. 11, pp. 3010, 2011.

[17] D. Kasote, Y. Badhe, A. Zanwar, M. Hegde, and K. Deshmukh, "Hepatoprotective potential of ether insoluble phenolic components of $n$-butanol fraction (EPC-BF) of flaxseed against CCl4-induced liver damage in rats," Journal of pharmacy \& bioallied sciences, vol. 4, no. 3, pp. 231, 2012.

[18] M. Shahjahan, K. Sabitha, M. Jainu, and C. S. Devi, "Effect of Solanum trilobatum against carbon tetra chloride induced hepatic damage in albino rats," Indian Journal of Medical Research, vol. 120, pp. 194-198, 2004.

[19] G. Robertson, I. Leclercq, and G. C. Farrell, "II. Cytochrome P-450 enzymes and oxidative stress," American Journal of Physiology-Gastrointestinal and Liver Physiology, vol. 281, no. 5, pp. G1135-G1139, 2001.

[20] K. Raju, G. Anbuganapathi, V. Gokulakrishnan, B. Rajkapoor, B. Jayakar, and S. Manian, "Effect of Dried Fruits of Solanum nigrum L INN against CCl4-Induced Hepatic Damage in Rats," Biological and Pharmaceutical Bulletin, vol. 26, no. 11, pp. 1618-1619, 2003.

[21] L. Ranawat, J. Bhatt, and J. Patel, "Hepatoprotective activity of ethanolic extracts of bark of Zanthoxylum armatum DC in CCl4 induced hepatic damage in rats," Journal of ethnopharmacology, vol. 127, no. 3, pp. 777-780, 2010.

[22] O. Adewale, A. Adekeye, C. Akintayo, A. Onikanni, and S. Sabiu, "Carbon tetrachloride (CCl4)-induced hepatic damage in experimental Sprague Dawley rats: Antioxidant potential of Xylopia aethiopica," Carbon tetrachloride (CCl4)-induced hepatic damage in experimental Sprague Dawley rats: Antioxidant potential of Xylopia aethiopica, vol. 3, no. 2, pp. 1-6, 2014.

[23] M. H. Abdulrazzaq, E. J. Khadeem, and S. S. Al-Muhammadi, "Hepatoprotective effect of Echinops tenuisectus (Compositae) on $\mathrm{CCl} 4$ induced hepatic damage in rats," Iraqi J Pharm Sci, vol. 17, no. 1, pp. 16-24, 2008.

[24] M. G. Sturgill, and G. H. Lambert, "Xenobiotic-induced hepatotoxicity: mechanisms of liver injury and methods of monitoring hepatic function," Clinical chemistry, vol. 43, no. 8, pp. 1512-1526, 1997.

[25] X. Zhao, "Hawk tea (Litsea coreana Levl. var. lanuginose) attenuates CC14-induced hepatic damage in Sprague-Dawley rats," Experimental and Therapeutic Medicine, vol. 5, no. 2, pp. 555-560, 2013.

[26] R. A. R. Elgawish, H. G. A. Rahman, and H. M. Abdelrazek, "Green tea extract attenuates CCl4-induced hepatic injury in male hamsters via inhibition of lipid peroxidation and p53-mediated apoptosis," Toxicology Reports, vol. 2, pp. 11491156, 2015.

[27] V. Jaishree, and S. Badami, "Antioxidant and hepatoprotective effect of swertiamarin from Enicostemma axillare against D-galactosamine induced acute liver damage in rats," Journal of ethnopharmacology, vol. 130, no. 1, pp. 103-106, 2010.

[28] K. Mani Senthilkumar, B. Rajkapoor, and S. Kavimani, "Protective effect of enicostemma littorale. against CCl4-induced hepatic damage in rats," Pharmaceutical biology, vol. 43, no. 5, pp. 485-487, 2005. 